OPEN ACCESS

Edited by:

Victoria Team,

Monash University, Australia

Reviewed by:

Satarupa Dasgupta,

Ramapo College, United States Jennifer K. Ptacek,

University of Dayton, United States

Bryan Abendschein,

Western Michigan University, United States

*Correspondence: Eryn Bostwick

e.n.bostwick@csuohio.edu

Specialty section:

This article was submitted to Health Communication,

a section of the journal

Frontiers in Communication

Received: 16 July 2021

Accepted: 31 January 2022

Published: 04 March 2022

Citation:

Bostwick E, Dunbar NE and Johnson AJ (2022) The Influence of

Risk, Location, and Relationship on Refusing an Event Invitation During the

COVID-19 Pandemic

Front. Commun. 7:742283.

doi: $10.3389 /$ fcomm.2022.742283

\section{The Influence of Risk, Location, and Relationship on Refusing an Event Invitation During the COVID-19 Pandemic}

\author{
Eryn Bostwick $^{1 *}$, Norah E. Dunbar ${ }^{2}$ and Amy Janan Johnson ${ }^{3}$ \\ ${ }^{1}$ School of Communication, Cleveland State University, Cleveland, $\mathrm{OH}$, United States, ${ }^{2}$ Department of Communication, \\ University of California, Santa Barbara, Santa Barbara, CA, United States, ${ }^{3}$ Department of Communication, University of \\ Oklahoma, Norman, OK, United States
}

Viewed through the lens of the Revelation Risk Model (RRM), we examined whether the perceived riskiness of an activity, relationship type (family, romantic, or friends), and location in the US (California, Oklahoma, or Ohio) influenced whether and how people communicated with close others when refusing an event invitation during the COVID-19 pandemic. Additionally, we examined how these factors affected their likelihood of attending an event, their likelihood of refusing an invitation, and their anticipation of the effect of the disclosure of their refusal on future interactions. States varied widely in their response to the pandemic and our results suggest this affected participants' responses to the activity scenarios we presented. People from Ohio and California reported less likelihood of attending the event in the high-risk condition than people from Oklahoma. Participants were more likely to make up false excuses for low-risk events to avoid conflict. A three-way interaction between riskiness of the scenario, closeness of the relationship type, and location predicted the effect on future interactions. Implications for the effects of refusals on relationships are discussed.

Keywords: disclosure, risk perception, refusals, interpersonal communication, CoVID-19

\section{INTRODUCTION}

The worldwide outbreak of COVID-19 in early 2020, and restrictions put in place to limit social gatherings, created a lot of stress for people around the world (Katella, 2020). While the easing of stay-at-home orders in some states across the US alleviated stress for some people, allowing them to leave their houses and maybe interact with loved ones again, for others a whole new layer of issues emerged: what to do when people invite you to an event you are not comfortable attending. This became a popular topic of concern, with news articles covering people's experiences as they reported engaging in conversations about their own comfort level and boundaries (Chapin, 2020; Ellison, 2020). Given the importance of avoiding contact with others to slow the spread of the virus prior to the availability of vaccines (O'Reilly, 2020), having honest conversations with loved ones about comfort levels and the risk involved with activities was extremely important.

While these conversations are imperative, they are not always successful and can have negative effects on relationships, particularly when one's assessment of the situation does not match the assessment of their relational partner (Chapin, 2020). Unfortunately, research suggests perceptions of risk and comfort are influenced by political rhetoric (Hardy, 2020), creating even more 
opportunity for frustration, blame, guilt, and potentially conflict. In some situations, if one's relational partner does not agree with their concerns, relationships can be permanently damaged (Ellison, 2020). Additionally, for some, just the thought of providing a refusal causes stress or fear that loved ones will blame them, making them feel guilty about not attending (Fetters, 2020). The potential negative outcomes associated with refusals might make it more likely people avoid having conversations and attend events they are uncomfortable with, or lie about their reason for not attending just so they can avoid the conversation (Whillans et al., 2020).

The anecdotal stories and research described above suggest that, at least for some people, engaging in important conversations about health protocols and comfort levels is a daunting task, and one that some might prefer to avoid. This provides a perfect scenario for communication scholars to examine the factors that influence decisions people make about refusing invitations from relational partners, should people be asked to engage in an activity they deem too risky, and how those resulting conversations influence interpersonal relationships. Therefore, this research seeks to better understand the experiences people have refusing event invitations during the COVID-19 pandemic. With research on refusals and the Revelation Risk Model (RRM) as a basic framework, the goal of this study is to determine how situational and relational factors influence three processes related to disclosures: (a) the likelihood someone will refuse an invitation to an event during the COVID-19 pandemic, (b) the communicative processes (direct vs. indirect) used to refuse the invitation, and (c) relational outcomes as a result of disclosing a refusal.

The insight provided by the results of this study will add to the current literature by examining how relational characteristics combine with a major global health crisis to influence refusal processes in personal relationships. Researchers believe being direct and honest in conversations about COVID-19 risk is best, and have found that being honest can actually bring people closer together (Whillans et al., 2020); therefore, results of this study will help practitioners understand different personal and relational characteristics that might put someone at risk of either avoiding refusal conversations or being indirect in their refusals surrounding COVID-19 so that they can work with them to make them more comfortable opening up and being direct.

\section{Literature Review \\ The COVID-19 Pandemic}

The COVID-19 pandemic began as the virus spread rapidly across the globe in the beginning of 2020. Although the virus was first confirmed in 2019, it was not until March of 2020 that it was declared a national emergency in the United States. By the end of March there were worldwide restrictions on travel, the Centers for Disease Control and Prevention (CDC) suggested limits on the number of people gathering together, and several US states shut down all non-essential business, with schools pivoting to online learning and many people working from home in an effort to keep people indoors and slow the spread of the virus (Bryson Taylor, 2020). Following stay at home orders, reports of stress, anxiety, and depression increased (Katella, 2020), and after one month protests against the health measures taken by state governments occurred in places like Michigan, Minnesota, and Ohio. By May and June 2020, some states started opening back up and easing quarantine restrictions (Bryson Taylor, 2020), while vaccines were not widely available in the US until spring and summer of 2021.

With the lifting of orders and nicer summer weather in 2020, the topic of conversation in many news outlets became how to handle requests to socialize with friends and family, and what to do if people are invited to an event they are not comfortable attending (Chapin, 2020; Ellison, 2020). Some people reported that these conversations were difficult and frustrating. For example, Chapin (2020) spoke with people who reported family members responding to their declaration of risk and comfort boundaries by saying they were being too cautious or loved ones who refused to compromise to match the comfort level of others. Conversations about comfort levels and boundaries during the pandemic require communicators to be vulnerable about their concerns, which opens them up to the possibility of being invalidated by their close relational partners. When there is a disagreement between relational partners, if their differing needs are not respected, it can have negative relational implications. For example, some people reported ending their friendships as a result of COVID-19 boundary differences (Ellison, 2020). Anticipated outcomes of these conversations can be so nervewracking, that some people might avoid having the conversations altogether. For example, Whillans et al. (2020) found people were more likely to say "yes" to attending an event when asked by a close friend, even if they were not comfortable. Additionally, turning down an invitation could count as a facethreatening act for invitees, or an act that inherently damages the positive self-image or sense of autonomy of one person by acting in opposition to the wants and desires of the other (Brown and Levinson, 1987). Ultimately, if not done carefully, refusals can cause relational harm (Tanck, 2002). Therefore, it is important researchers understand what kind of factors influence the likelihood that people might be in a position to refuse an invitation, as well as how those factors influence one's refusal strategy and the implications for the relationship after the refusal has taken place.

To examine these processes, we rely on the Revelation Risk Model and the concept of refusals as frameworks that help us understand the influence of a variety of factors that could contribute to someone's decision to turn down (i.e., refuse) an event invitation during the COVID-19 pandemic. The decision to provide a refusal is likely complicated; therefore to account for this our study seeks to examine the role of both situational (risk level and location within the US) as well as relational (relationship type: family, romantic relationship, or friendship) influences on people's communicative experiences when refusing an invitation to an event during the COVID-19 pandemic.

\section{Refusals and the Revelation Risk Model}

A refusal occurs when a speaker either "directly or indirectly says 'no' to a request or invitation” (Tanck, 2002, p. 2). Direct refusals involve specifically saying "no" in some capacity, whereas indirect refusals are vaguer and might contain excuses as to 
why someone cannot complete the request. Importantly, because refusals involve rejecting someone, they are considered facethreatening acts. Because of this, indirect refusals are more common than direct ones, as they allow people to say no while still being polite and saving face (Tanck, 2002).

The first step in understanding the refusal process associated with social gathering invitations during COVID-19 is to determine what circumstances might lead to needing to provide a refusal in the first place. At its most basic, those who do not feel comfortable attending are the most likely to refuse an event invitation. However, the decision to refuse an invitation is likely more nuanced, given the frustration and conflict people have reported in their actual conversations with loved ones (Chapin, 2020; Ellison, 2020), particularly considering reports people have attended events they do not feel comfortable with in order to avoid having to refuse someone (Whillans et al., 2020). Therefore, in order to get a more holistic understanding of the refusal process, it is important to consider the variety of factors that contribute to decisions to disclose a refusal.

One framework that can help scholars understand the decision to refuse an invitation is the Revelation Risk Model (RRM). The RRM was initially developed by Afifi and Steuber (2009) as a model utilized to predict circumstances that lead to secret disclosure specifically. Although this model does not examine refusals, it does consider how factors influence people's decision to disclose information to close others. Importantly, the RRM is relevant to the refusal process examined here because it considers not just the individual considering disclosure, but also how their relationship with their disclosure target plays a role in the decision to disclose (Afifi and Steuber, 2009).

According to the RRM, when deciding whether to disclose to someone individuals consider the risk associated with disclosure, and the higher the risk the less likely they are to disclose. When assessing the risk of disclosure, people consider 1) the risk to themselves, 2) the risk to their relationship, and 3) the risk to other people. Evaluation of self-risk involves protecting oneself from negative evaluations, like judgment, ridicule, or harm. Evaluation of relationship-risk involves trying to protect one's relationship with the disclosure target from harm. Lastly, evaluation of risk to others involves considering how other people might be impacted by one's disclosure (Afifi and Steuber, 2009). In the context of invitation refusals during the COVID19 pandemic, self-risk could involve concerns such as how one's relational partner might judge them for their COVIDrelated beliefs, while relationship-risk would be focused on how their relationships might be impacted by refusing an invitation, and risk to others might involve considering whether it is important to directly address the health risks associated with event attendance in order to protect others.

Additionally, the model also considers conditions under which people would be more willing to disclose. In the context of secrets, these conditions are 1) the need for catharsis, 2) feeling like the disclosure target needs to know the information, and 3) being asked by another person to reveal the information (Afifi and Steuber, 2009). Given that this study is not focused on secrets, we have used the basic premise of the RRM to examine what factors might influence someone's decision to refuse an invitation to an event during the COVID-19 pandemic. While the conditions that influence disclosure are not the same, because of the potential negative ramifications of engaging in discussions about the risk of social gatherings and the harm these conversations could pose to relationships, the general premise of RRM can be a helpful framework for unpacking the refusal process. This is particularly true if people anticipate a negative reaction from the individual who invited them (e.g., if the person does not think the invitee will agree with their decision and might get upset). To understand how individuals might weigh the risk of providing a refusal, it is important to first identify factors that might influence when a refusal would take place, beginning with conditions under which someone might not be comfortable attending an event.

One of the factors that should influence whether someone is comfortable attending an event is the level of COVID-19 related health risks associated with the event in question. In theory, the higher the risk associated with an activity, the less comfortable someone should be attending the event and the more likely someone should be to refuse an invitation. However, research on risk has found that one's perception of risk is more predictive of their behavior than the actual risk (Turner et al., 2011) and research on risk perceptions of COVID-19 specifically have found that misconceptions are common (Faasse and Newby, 2020). Therefore, it is not surprising that many news articles during the late spring and early summer months of 2020 reported on the risk of various common activities. For example, Moitke (2020) and DesOrmeau (2020) spoke with health experts to rank the risk of various summer activities. The CDC even created a searchable page people could use to learn about risks associated with various activities and steps people should take to reduce their chances of getting themselves or others sick (CDC, 2020). Even with these resources available and widely disseminated, it does not guarantee people will accurately understand risk, especially because research has found people differ in their trust of news sources and expert opinion during the COVID-19 pandemic (Hardy, 2020). Thus, in order to understand how risk influences comfort level, it is necessary to examine other factors that influence people's risk perceptions.

One additional factor that might influence how people perceive the health risk associated with various activities during the COVID-19 pandemic is their location because of the partisanship that has been associated with reactions to public health measures in the US during the pandemic (Gadarian et al., 2021; Ye, 2021). Vai et al. (2020) found COVID risk perceptions and behavioral intentions varied by location when comparing personal beliefs of those in Italy vs. Japan. There are multiple reasons to believe perceptions of COVID-19 would vary not just between residents of different countries, but also between residents of different locations within the United States.

Responses to the pandemic have varied widely by state. For example, as of November 2020, California still had stay at home orders in place, whereas many other states around the country lifted their orders as early as May. Additionally, some states, like Massachusetts, had limits on the number of people who could gather at one time, while others had no such restrictions (Kaiser Family Foundation, 2020). Some states 
varied the types of business that could open while others had blanket orders that covered all business types (like restaurants and gyms) (Adolph et al., 2021). One of the explanations for widely different responses by state is political affiliation of the leaders, especially the state's Governor who were the ones making policies. For example, Adolph et al. (2021) examined COVID19 protocols at the state level and found that Governors of Republican states began to ease lockdown restrictions or stayat-home orders 14.5 days earlier than Governors of Democratic states, regardless of actual transmission or hospitalization rates. The Governors of Florida and Texas (both Republican-leaning states with Republican leaders) signed executive orders banning mask mandates by schools in their states. The Arizona Legislature did the same (Lombardo, 2021). Thus, by examining the policies of states by their leaders' party, Adolph et al. were able to track the partisan effects on virus transmission and compliance with COVID-19 policies like stay-at-home orders.

Importantly, in the United States, it is a common practice by the media to color-code states where red designates a state voting mostly Republican and blue designates a state voting mostly Democratic. A few states are known as "purple" which means they swing back and forth from election to election (Rader, 2019). Makridis and Rothwell (2020) utilized this color-coding system in their research and found political partisanship based on states' electoral college votes in the 2016 election influenced the types of policies states put into place to help quell the virus, with states that were "red" in 2016 being $20 \%$ less likely to adopt a statewide shut down order and $40 \%$ less likely to enforce a mask mandate compared to those that were "blue" (Makridis and Rothwell, 2020). Lastly, partisanship appears to affect vaccination rates as well. Ye (2021) examined vaccination rates by US county and found a widening gap over time between Democratic-leaning and Republican-leaning counties when tracking vaccination rates from January to May 2021 as vaccines were rolled out and made more available to younger cohorts.

The research described above has found a link between one's location and their perceptions of health risk during the COVID-19 pandemic, as well as a link between their location and their comfort engaging in various risk-preventing behaviors. Therefore, it is likely both COVID risk and one's location influence a person's comfort attending certain events, and the likelihood they do attend the event. However, given the connection between state decisions and party affiliation, much of the research has focused on the difference between red states and blue states, but little is known about how residing in a "purple" state, or swing-state, might influence risk perceptions. With this in mind, the following hypothesis was posed:

H1: COVID risk level and location will interact to influence one's (a) comfort level and (b) likelihood of attending an event during the COVID-19 pandemic.

Lastly, although comfort level should determine whether someone accepts an invitation to an event during the COVID19 pandemic, some research suggests relationship type influences how likely someone is to attend an event regardless of comfort level, which aligns with the importance placed on relationships in the RRM. For example, Whillans et al. (2020) found people were more likely to accept an invitation they were uncomfortable with when the invitation came from a friend than from a family member or colleague. Therefore, relationship type seems to interact with risk level of activities to influence likelihood of attending an event, although Whillans et al. (2020) did not include romantic partners in their analysis, so the insight provided by that research is incomplete. Additionally, little is known about how and whether one's location might influence the connection between relationship type and willingness to attend an event. Therefore, the following research question was posed:

RQ1: Does relationship type interact with (a) COVID risk level, (b) location, or (c) COVID risk level and location to predict the likelihood someone will attend an event during the COVID19 pandemic?

\section{Strategies to Disclose a Refusal}

The next step in understanding the invitation refusal process during the COVID-19 pandemic is trying to determine how people let others know they do not want to attend the event. Based on the RRM, people are more likely to avoid disclosure if they anticipate a negative reaction and/or if the topic of disclosure is considered negative (Afifi and Steuber, 2009); however, in this particular context completely ignoring an invitation to an event is unlikely, as doing so would be considered rude. Beyond simply disclosing or keeping a secret, the RRM does identify specific communication strategies people use to disclose secrets, including directness, indirect mediums, incremental disclosure, third party revelations, preparation/rehearsal, and entrapment (Afifi and Steuber, 2009). Given that refusals tend to be indirect (Tanck, 2002), it is thus important to consider indirect strategies people might use to refuse an invitation. One indirect strategy might be to lie about the reason why they do not want to attend. For example, if someone is worried the invitee will react negatively if they admit they are not comfortable attending the event because of the risk it poses, they might instead say they are busy. In fact, Afifi and Guerrero (2000) found one way people avoid sensitive topics when they cannot or will not avoid the conversation altogether is to purposefully leave out information, essentially engaging in deception as an avoidance tactic.

Additionally, Hancock et al. (2009) coined the term "butler lies" as a type of deception used to manage the entry and exit of social interactions and avoid interactions altogether. Although they were talking about technology like instant messaging taking the place of the Butlers of the elite in a bygone era, they emphasized an important point, which is that politeness is the motivation for many of our everyday deceptions. People seek to maintain their own and their partner's "face." As Hancock et al. (2009) state,

As Brown and Levinson point out, people use different language strategies to avoid threatening one's own or another's face. Deception is one language strategy (an 'off-the- record' strategy in the Brown and Levinson terminology) that we use when committing a face-threatening act...Butler lies about avoiding an interaction, or lies related to leaving a conversation that the 
partner wants to continue, are designed to maintain our own face (not coming across as mean or haughty) as well as our partner's (that we respect and like them) (p. 519).

Similarly, we can use polite forms of deception to avoid talking about difficult topics to avert a conflict or to spare our partner's feelings. We can also refuse an invitation but give an excuse in order to preserve our own autonomy and control over our own bodies during a dangerous pandemic. The above research suggests lying when responding to an event invitation is a possibility, but are there ever times people might decide honesty is more important than keeping others happy?

Keating et al. (2013) examined how topic avoidance functioned when it came to difficult conversations. They predicted one's family communication patterns would influence whether one engaged in a difficult conversation, with those that came from very open families where different opinions are encouraged being more willing to engage in conversations than those who come from families who discuss few topics together and stress homogeneity of values. However, contrary to their predictions, their results suggested everyone regardless of their family communication patterns engaged in difficult conversations. Keating et al. (2013) asserted their results highlight the fact that when the situation surrounding the difficult conversation is considered critical, avoidance of the conversation is unlikely.

Given that attendance at events during the COVID-19 pandemic has been linked to the spread of the virus and even death of attendees in some cases (Zdanowicz and Jackson, 2020), there are likely at least certain event contexts that align with the critical situations Keating et al. (2013) highlighted in their research. Because engagement in difficult conversations was only likely when the situation is deemed critical, risk level of the activity in question should influence whether someone lies or is honest when rejecting an invitation. For example, based on Keating et al.'s (2013) findings, people might be more likely to honestly reject an invitation to a high-risk event like an indoor mask-less gathering in a crowded bar, compared to a moderate or low-risk event, such as an outdoor dinner or going for a walk outdoors with masks on and social-distancing measures in place. Interestingly, Whillans et al. (2020) found $73.8 \%$ of people wanted to communicate the risk associated with an activity to their loved one when rejecting an invitation to an event, but only $45.5 \%$ reported they would express concerns with risk when providing an excuse. They found regardless of political orientation, people were more likely to be honest about their concerns when they worried about the event harming the welfare of their friend, and suggested risk for one's friend was the biggest determinant of whether people were honest (Whillans et al., 2020).

According to the RRM, relationship characteristics should also influence one's willingness to be honest. For example, relational closeness has been positively associated with disclosure, suggesting close relationships provide people with a sense of safety, allowing them to feel like it is safe to be honest. Caughlin et al. (2005) found people more willing to disclose to people they are close to and Derlega et al. (2008) found relational closeness as a frequently mentioned reason for being willing to disclose highly personal information. Laursen and Williams (1997) found those relationships that are horizontal (i.e., relatively equal in power and status) and voluntary, such as friendships and romantic relationships, are considered closer than those that are vertical (i.e., relatively unequal in power and status) and involuntary, such as family relationships. Additionally, Derlega et al. (2008) found both willingness to truthfully disclose highly personal information and reasons for disclosure varied by relationship type. Lastly, Godbersen et al. (2020) found relationship type influenced perceptions of the effectiveness and importance of social distancing, with concerns about close family members being more influential than concerns about friends. When considered in combination with the focus on other-risk in the RRM, all the above research suggests one's relationship to the invitee might influence how worried a person is about COVID risks and therefore how willing they are to directly and honestly address their concerns.

Based on the research cited above, we believe that the closeness of the relationship and the risk level will affect the truthfulness or deceptiveness of the reasons provided. Thus, the following hypothesis was proposed:

H2: Relationship type and COVID risk level will interact to predict truthfulness of an excuse provided when declining an invitation to an event during the COVID-19 pandemic.

\section{Relational Implications of Refusals}

Considering the importance of relationships in the RRM, the last step in understanding people's experiences with refusals during the COVID-19 pandemic is to examine the relational implications of rejecting an invitation. News reports of conversations related to event invitations during the pandemic support the idea that some people experienced negative relational implications. For example, when describing an upsetting situation with a friend, Ellison (2020) interviewed someone who indicated she did not talk to a friend for two weeks after that friend insisted she come to an event that she was uncomfortable attending. The whole situation was frustrating, she claimed, because her friend promised the circumstances were safe and tried to persuade her to attend by asking if she trusted them. Because of her friend's claims, and the trust she had for this friend, she went to the event; however, when she arrived, she felt the situation was too risky and left at once (Ellison, 2020). In this case, according to the individual interviewed, once she realized her friend's comfort level and hers were not the same, her perception of her friend changed and their relationship suffered, at least in the short term.

The example above suggests it is likely people perceive their relationships will be negatively impacted as a result of declining an invitation; however, this process is likely influenced by COVID risk level associated with the event, location, and relationship type. In general, people fear negative relationship implications because they worry their relational partner will be upset by their disclosure, or the disclosure itself will cause conflict (Afifi and Steuber, 2009). In the context of COVID-19 event invitations, those who decline an invitation and expect their relational partner to be disappointed and/or angry should fear a negative outcome as a result of their refusal of the invitation, whereas 
those that accept the invitation should experience positive relationship outcomes. This means in order to determine how risk, location, and relationship type might influence relational outcomes, one must consider how these factors might lead to the requestor becoming upset and/or the refusal leading to conflict in the first place.

In terms of COVID-19 risk level, it is more likely people would be upset when someone declines an invitation to a lowrisk event than a moderate or high-risk event. This is because declining a moderate or high-risk event invitation would likely be expected, whereas people would be less likely to expect a rejection to a low-risk event. Therefore, people should report worse relationship outcomes when rejecting an invitation from a lowrisk event than a moderate or high-risk event. However, given the influence of location on one's perception of risk described earlier, location should also influence whether someone gets upset because a loved one declined an invitation. According to Lenz (2013), constituents form their own opinions about public issues based on the positions of political elites. The opinions of elites have the power to either encourage people to engage in safe practices, or to reject suggestions supported by scientific research (Darmofal, 2005; Brulle et al., 2012). This means policy decisions of local officials, as well as their public messaging about the risk of contracting COVID-19, have the power to influence individual beliefs about the risk of certain events, and in turn whether someone would be upset by an event refusal. For example, based on Lenz's (2013) research, someone who lives in an area with public officials who denounce mask mandates and suggest constituents should not be afraid to eat indoors or attend events would likely be influenced by the opinions and messages provided by their officials, ultimately believing that event attendance is less risky than it really is. Because of these beliefs they would also be more likely to get upset when someone refuses an event invitation they have extended, perhaps ultimately believing the invitee is being unnecessarily worrisome. Conversely, someone who lives in an area with public officials who support mask mandates and encourage constituents to only congregate outside and always follow social distancing measures would be more likely to believe event attendance is too risky. Because of these beliefs they would be more likely to understand why someone refused an invitation and would therefore not get upset at receiving a refusal. In the context of state politics, given that blue states had a higher likelihood of instilling strict safety measures compared to red states (Makridis and Rothwell, 2020; Adolph et al., 2021), when declining an invitation to an event during COVID-19, those from red states should expect poorer relationship outcomes as a result of declining an invitation than those from blue states, even if the risk is high. Therefore, the following hypothesis was proposed:

H3: COVID risk level and location will interact to predict relational implications after declining an event invitation during the COVID-19 pandemic.

Lastly, relationship type could influence perceptions of relational implications. For example, Furman and Buhrmester (1992) found friendships and romantic relationships were more egalitarian than parent-child relationships, and research has shown when someone has less power they are more likely to experience psychological aggression from their relational partner (Dunbar and Johnson, 2015). Additionally, Warner et al. (2020) found when people disagree with their family members, they are less likely to engage in respectful communication when discussing those differences. Therefore, people might expect worse relationship outcomes when declining an event from a family member than a friend or romantic partner. However, given descriptions of people ending relationships because of frustrations after engaging in COVID-19-related conversations (Ellison, 2020), it is possible people are more worried about seriously harming voluntary relationships, like friendships and romantic relationships, than involuntary relationships, like family relationships. For example, Roper et al. (2018) found people anticipated more relational harm following an aggressive argument with a romantic partner than a family member and the authors suggested this might be because family relationships are more stable and more difficult to end. All in all, the influence of relationship type on the future of one's relationship seems uncertain, and when combined with information about the influence of risk and location it is unclear how all three factors will influence perceptions of the relationship together. Therefore, the following research question was posed:

RQ2: Do COVID risk level, location, and relationship type interact to predict perceived impacts of an invitation refusal on the future of a relationship?

\section{MATERIALS AND METHODS}

\section{Participants}

An online survey circulated between September and October 2020 was compiled via Qualtrics from the scales listed below and completed by undergraduate students in three different states meant to represent blue [California $(n=131)$ ], red [Oklahoma, $(n=172)$ ], and purple ${ }^{1}$ [Ohio $(n=78)$ ] states in the summer and early fall of 2020. Subjects were recruited at large Universities in each state through research pools and courses in three different Departments of Communication. To qualify to participate, individuals needed to be at least 18 years of age and enrolled in an undergraduate communication course. A total of 451 people began the survey, but after deleting those surveys that were completed in $<10 \mathrm{~min}$ and two surveys that were almost completely blank, a total of 381 completed surveys were utilized for analysis. Those who completed the survey were compensated with extra credit to apply to their communication courses. During the pandemic, some College students were telecommuting from other locations, but the majority were still residing in the state where they attend University (California, 88.5\%; Oklahoma, 82.6\%; Ohio, 97.4\%).

Age of the participants ranged from 18 to $60(M=20.56$, $S D=4.11)$. The majority of participants identified as female $(n=282,74 \%)$, while $24.7 \%$ identified as male $(\mathrm{n}=94)$, one

\footnotetext{
${ }^{1}$ From 2000 to 2016, Ohio voted for the Republican Presidential Candidate 3 times and the Democratic Candidate twice. During that time, they elected Republican Senators 5 times and Democrats 4 times. In California, all Presidential Candidate winners and Senators have been Democratic and in Oklahoma all have been Republican during the same span.
} 
person (0.3\%) identified as non-binary, and four people did not provide this information. A majority of the participants identified as white $(n=246 ; 64.6 \%), 15.7 \%$ identified as Asian or AsianAmerican $(n=60), 9.7 \%$ identified as Hispanic or Latino/a $(n=$ 37), 3.9\% identified as Black or African American $(n=15), 2.1 \%$ identified as American Indian or Indigenous North American ( $n$ $=8$ ), and $2.9 \%$ indicated "other" as their racial/ethnic identity, with answers ranging from a mixed identity to Middle Eastern. Lastly, on average participants reported wearing a mask $85.32 \%$ of the time when they left their home and were within $6 \mathrm{ft}$ of another person.

\section{Measures COVID Risk Level}

To understand the role of risk and relationship type on event invitation refusals, the authors developed a total of nine vignettes, which were randomly presented to participants. In the vignettes, three different relational partners were accounted for (friend, family member, and romantic partner) and within each relationship type category, the authors created three different situational activities, one of low-risk, one of moderate-risk, and one of high-risk. Risk of each situation was determined based on the rankings of the Texas Medical Association Chart (Texas Medical Association, 2020). See Appendix A for a list of the vignettes associated with each relationship type and risk level, as well as information concerning the number of participants assigned to each of the nine vignettes.

Participants were randomly presented with one vignette for each relationship type (for a total of three), asked to think of a person in their life that represented that relationship type (ex: think of a close friend, think of a sibling, think of a current or imagined romantic partner) and write their initials down to help them remember who they were thinking of. In order to simulate the refusal process, they were then presented with the scenario and asked various questions about their comfort attending the activity, their likelihood of attending the activity, the excuse they would provide to the invitee when refusing an invitation, the truthfulness of their excuse, and their perception of future interactions with this person as a result of their conversation.

\section{Comfort With Activity}

Comfort was measured with one item asking participants to indicate how comfortable they would be attending the activity described in the vignette on a scale of 1 (Extremely Comfortable) to 7 (Extremely Uncomfortable). The item was reverse coded so that higher levels meant more comfort, $M=4.93, S D=2.09$.

\section{Likelihood of Attending Activity}

Likelihood of attending the activity was measured with one item asking participants to indicate how likely they would be to attend the activity described in the vignette on a scale of 1 (Extremely Likely) to 7 (Extremely Unlikely). The item was reverse coded so that higher levels meant a higher likelihood of attending, $M=$ $4.98, S D=2.16$.

\section{Deception}

Deception used in the excuse participants provided was measured using one item asking participants to rate the truthfulness of the excuse they provided on a 1 (Definitely True) to 5 (Definitely False) scale, $M=1.56, S D=0.91$.

\section{Perceptions of Future Interactions}

To determine how participants predicted future interactions with their relational partner might go, participants were asked to consider, based on their response to the person's request to engage in an activity, how they anticipated their future interactions with the person would be. This question was developed by the authors. The question utilized 10 items on a 7point semantic differential scale. Examples of options included, positive vs. negative, satisfying vs. unsatisfying, more sad vs. happier, and closer vs. more distant. Some items were reversecoded so that a higher score reflected a negative impact on future interactions, Reliabilities ranged from $\alpha=0.95-0.97$ across the nine scenarios, $M=2.05, S D=1.12$.

\section{Covariates}

When conducting hypothesis tests the authors controlled for a variety of factors, including age, sex, the percentage of time one reported wearing a mask, risk perception accuracy, risk aversion, perceived stress, and closeness between the participant and the individual extending the invitation.

Risk accuracy was determined by presenting participants with a list of common activities found on the Texas Medical Association's risk assessment scale provided on the Texas Medical Association website, 2020. The authors selected this list because it was compiled by medical experts and was widely publicized and cited by several popular news sources in the summer of 2020. It ranks 37 different activities on a scale from 1 to 10,1 being the least risky and 10 being the most. Examples of activities ranked on the list include playing tennis, shopping in a mall, and going to a bar. Participants were randomly presented with 20 of the 37 activities, told medical authorities had ranked each activity on a scale of 1-10 based on how risky each activity was, and were asked to rank each of the 20 activities on a 1-10 risk scale themselves. Risk accuracy was then determined by calculating an absolute value of the differential between each person's rankings and the rankings of the Texas Medical Association, which ranged from 15 to $99, M=39.28, S D=13.65$. For this item, scores closest to zero would be considered more accurate.

Risk aversion was measured using the General Risk Aversion scale by Mandrik and Bao (2005). This scale presents participants with six statements on a 1 (Strongly Disagree) to 7 (Strongly Agree) Likert scale, asking them to indicate how much they agree or disagree with each statement. Example statements include, "I do not feel comfortable taking chances" and "Before I make a decision, I like to be absolutely sure how things will turn out." One item was dropped from the scale due to poor reliability, after the item was dropped, $\alpha=0.75, M=3.34, S D=1.00$.

Perceived stress was measured using Cohen et al.'s (1983) Perceived Stress scale. This scale presents participants with four statements on a 0 (Never) to 4 (Very Often) Likert scale, asking them to indicate how often they have felt or thought in a certain way. Example statements include, "In the last month, how often have you felt that things were going your way?" and "In the last month, how often have you felt difficulties were piling up so high 
that you could not overcome them?" Higher numbers on this scale meant more stress, $\alpha=0.72, M=2.48, S D=0.53$.

Relational closeness was measured using Aron et al.'s (1992) Inclusion of Other in the Self scale. This scale uses Venn diagrams to help participants visualize closeness in their relationships. In the diagram, one circle represents the participant and the other circle represents their relational partner. The participants are presented with seven different Venn diagrams, with different amounts of overlap between the circles in each one. The circles go from 1 (Not Touching) to 7 (Almost Completely Overlapping). Participants were asked to indicate which diagram best represented their relationship with the person they associated with each vignette, $M=5.08, S D=1.76$.

\section{RESULTS}

All hypotheses and research questions were tested with a MANCOVA that examined the independent variables of level of risk (low, moderate, high), type of relationship (family, friend, romantic partner), and location of participant (the red state of Oklahoma, the blue state of California, and the purple state of Ohio, as designated in terms of typical political leanings of the state's populations). Significant covariates included participant age, Wilks' $\lambda=0.96, F_{(5,814)}=6.53, p<0.001$, partial $\eta^{2}=0.04$; sex, Wilks' $\lambda=0.98, F_{(5,814)}=2.88, p=0.01$, partial $\eta^{2}=0.02$; percent of time they reported wearing a mask, Wilks' $\lambda=0.94$, $F_{(5,814)}=11.17, p<0.001$, partial $\eta^{2}=0.06$; their general risk aversion, Wilks' $\lambda=0.94, F_{(5,814)}=11.32, p<0.001$, partial $\eta^{2}=0.07$; their relational closeness with the individual about whom they were reporting, Wilks' $\lambda=0.78, F_{(5,814)}=45.12, p<$ 0.001 , partial $\eta^{2}=0.22$; their accuracy in assessing the riskiness of the activity presented in the scenario, Wilks' $\lambda=0.98, F_{(5,814)}$ $=3.46, p<0.01$, partial $\eta^{2}=0.02$; and their perceived stress levels in the last month, Wilks' $\lambda=0.99, F_{(5,814)}=2.28, p<0.05$, partial $\eta^{2}=0.01$.

The multivariate test of the MANCOVA showed a significant main effect for the riskiness of the scenario, Wilks' $\lambda=0.75$, $F_{(10,1,628)}=25.65, p<0.001$, partial $\eta^{2}=0.14$. Significant univariate effects for riskiness of scenario included comfort with the proposed activity, $F_{(2,818)}=127.91, p<0.001$, partial $\eta^{2}=$ 0.24 ; likelihood of attending proposed activity, $F_{(2,818)}=94.21, p$ $<0.001$, partial $\eta^{2}=0.19$; and deception level in response to the request, $F_{(2,818)}=6.77, p=0.001$, partial $\eta^{2}=0.02$. See Table 1 for means and standard deviations for each riskiness condition (low, moderate, high).

The multivariate test also showed a significant main effect for the type of relationship about which they were asked to report, Wilks' $\lambda=0.96, F_{(10,1,628)}=3.00, p=0.001$, partial $\eta^{2}=0.02$. Significant univariate effects for type of relationship included comfort with the proposed activity, $F_{(2,818)}=4.95, p=0.007$, partial $\eta^{2}=0.01$; and likelihood of attending proposed activity, $F_{(2,818)}=4.83, p=0.008$, partial $\eta^{2}=0.01$. See Table 2 for means and standard deviations for each relationship type (friend, romantic partner, family member).

The multivariate test showed a significant main effect for the location of data collection, Wilks' $\lambda=0.95, F_{(10,1,628)}=4.25$,
TABLE 1 | Means and standard deviations by riskiness of scenario.

\begin{tabular}{llll}
\hline & Low risk & Moderate risk & High risk \\
\hline Comfort & $5.14_{\mathrm{a}}(1.34)$ & $3.15_{\mathrm{b}}(2.12)$ & $2.99_{\mathrm{b}}(2.17)$ \\
Attend? & $4.99_{\mathrm{a}}(1.57)$ & $3.25_{\mathrm{b}}(2.26)$ & $3.09_{\mathrm{b}}(2.25)$ \\
Future interaction & $2.18_{\mathrm{a}}(1.18)$ & $2.02_{\mathrm{a}}(1.16)$ & $2.16_{\mathrm{a}}(1.14)$ \\
Deception level & $1.76_{\mathrm{a}}(0.99)$ & $1.55_{\mathrm{b}}(0.94)$ & $1.43_{\mathrm{b}}(0.81)$
\end{tabular}

Within each row, means with different subscripts are significantly different from each other at $\alpha=0.05$. A higher score on comfort corresponds to greater comfort with the activity. $A$ higher score on attend signifies a higher likelihood of attending an event. A higher score on future interaction corresponds to a more negative impact on future interactions. A higher score on deception level indicated greater levels of deception.

TABLE 2 | Means and standard deviations by relationship type.

\begin{tabular}{lccc}
\hline & Friend & Romantic partner & Family member \\
\hline Comfort & $3.55_{\mathrm{a}}(2.08)$ & $3.63_{\mathrm{b}}(2.25)$ & $3.94_{\mathrm{b}}(2.13)$ \\
Attend? & $3.46_{\mathrm{a}}(2.19)$ & $3.81_{\mathrm{b}}(2.31)$ & $3.92_{\mathrm{b}}(2.19)$ \\
Future interaction & $2.16_{\mathrm{a}}(1.15)$ & $2.03_{\mathrm{a}}(1.14)$ & $2.15_{\mathrm{a}}(1.19)$ \\
Deception level & $1.69_{\mathrm{a}}(1.01)$ & $1.52_{\mathrm{a}}(0.84)$ & $1.61_{\mathrm{a}}(0.93)$ \\
\hline
\end{tabular}

Within each row, means with different subscripts are significantly different from each other at $\alpha=0.05$. A higher score on comfort corresponds to greater comfort with the activity. A higher score on attend signifies a higher likelihood of attending an event. A higher score on future interaction corresponds to a more negative impact on future interactions. A higher score on deception level indicated greater levels of deception.

TABLE 3 | Means and standard deviations by location of data collection.

\begin{tabular}{llll}
\hline & California & Oklahoma & Ohio \\
\hline Comfort & $3.04_{\mathrm{a}}(2.16)$ & $4.17_{\mathrm{b}}(1.99)$ & $3.60_{\mathrm{c}}(2.27)$ \\
Attend? & $2.96_{\mathrm{a}}(2.29)$ & $4.24_{\mathrm{b}}(2.01)$ & $3.66_{\mathrm{c}}(2.33)$ \\
Future interaction & $2.37_{\mathrm{a}}(1.20)$ & $1.91_{\mathrm{b}}(0.98)$ & $2.23_{\mathrm{a}}(1.40)$ \\
Deception level & $1.55_{\mathrm{a}}(0.91)$ & $1.59_{\mathrm{a}}(0.93)$ & $1.59_{\mathrm{a}}(0.91)$ \\
\hline
\end{tabular}

Within each row, means with different subscripts are significantly different from each other at $\alpha=0.05$. A higher score on comfort corresponds to greater comfort with the activity. A higher score on attend signifies a higher likelihood of attending an event. A higher score on future interaction corresponds to a more negative impact on future interactions. A higher score on deception level indicated greater levels of deception.

$p<0.001$, partial $\eta^{2}=0.03$. Significant univariate effects for location included comfort with the proposed activity, $F_{(2,818)}$ $=10.79, p<0.001$, partial $\eta^{2}=0.03$; likelihood of attending proposed activity, $F_{(2,818)}=15.31, p<0.001$, partial $\eta^{2}=0.04$; and predicted positivity of future interaction with the individual requesting, $F_{(2,818)}=5.91, p=0.003$, partial $\eta^{2}=0.01$. See Table 3 for means and standard deviations for each location of data collection (California, Oklahoma, Ohio).

In addition, the multivariate test showed that the interaction between relationship type and riskiness of scenario was significant, Wilks' $\lambda=0.90, F_{(20,2,701)}=4.24, p<0.001$, partial $\eta^{2}=0.03$. Significant univariate effects for the interaction between relationship type and riskiness of scenario included comfort with the proposed activity, $F_{(4,818)}=8.98, p<0.001$, partial $\eta^{2}=0.04$; and likelihood of attending proposed activity, $F_{(4,818)}=14.99, p<0.001$, partial $\eta^{2}=0.07$. The multivariate 
test also showed a significant interaction between location and riskiness of scenario, Wilks' $\lambda=0.96, F_{(20,2,701)}=1.88, p=0.01$, partial $\eta^{2}=0.01$. Significant univariate effects included comfort with the proposed activity, $F_{(4,818)}=3.78, p=0.005$, partial $\eta^{2}$ $=0.02$; likelihood of attending proposed activity, $F_{(4,818)}=3.40$, $p=0.009$, partial $\eta^{2}=0.02$; and predicted positivity of future interaction with the individual requesting, $F_{(4,818)}=3.13, p=$ 0.01 , partial $\eta^{2}=0.02$.

Finally, the three-way interaction between riskiness of scenario, relationship type, and location was also significant for the multivariate test, Wilks' $\lambda=0.93, F_{(40,3,551)}=1.44, p=0.04$, partial $\eta^{2}=0.01$. Significant univariate tests included predicted positivity of future interaction, $F_{(8,818)}=3.09, p=0.002$, partial $\eta^{2}=0.03$.

Now, each hypothesis test and research question will be discussed along with the relevant results from above. Hypothesis one claimed that risk level and location would interact to influence comfort level and likelihood of attending the event illustrated in the vignette. The interaction between risk level and location on comfort was significant, $F_{(4,818)}=3.78, p<0.01$, partial $\eta^{2}=0.02$ (see Figure 1). In addition, the interaction between risk level and location on likelihood of attending an event was also significant, $F_{(4,818)}=3.40, p<0.01$, partial $\eta^{2}=$ 0.02 (see Figure 2). Thus, hypothesis one was supported.

Research question one asked if there were interactions between the variables risk level, location of data collection, and type of relationship presented in the vignette to predict likelihood of attending a particular event during the pandemic. Relationship type and risk level interacted to predict likelihood of attending the event presented in the vignette, $F_{(4,818)}=14.99, p<0.001$, partial $\eta^{2}=0.07$ (see Figure 3 ). No other interactions including relationship type significantly predicted likelihood of attending.

Hypothesis two claimed that relationship type and risk level would interact to predict the truthfulness of the excuse provided when declining an invitation to an event during the COVID19 pandemic. The interaction between relationship type and risk level did not significantly predict truthfulness, $F_{(4,818)}=2.18, p=$ 0.07 , partial $\eta^{2}=0.01$. Thus, hypothesis two was not supported.

Hypothesis three asked whether risk level and location interacted to predict future relationship implications. Risk level and location interacted to significantly predict future relational implications, $F_{(2,818)}=3.13, p=0.01$, partial $\eta^{2}=0.02$ (see Figure 4), supporting hypothesis three. Additionally, research question two asked whether risk level, location of data collection, and relationship type interacted to predict the perceived impacts of invitation refusals on the future of the relationship about which the participant was reporting. This predicted three-way interaction was significant, $F_{(8,818)}=3.09, p=0.002$, partial $\eta^{2}=$ 0.03 (see Figure 5). In fact, the three-way interaction between risk level, location of data collection, and relationship type superseded the interaction between risk level and location predicted by hypothesis three.

\section{DISCUSSION}

Conversations surrounding risk and comfort attending events during the COVID-19 pandemic have caused dilemmas for individuals' interpersonal relationships, particularly when people's perceptions of risk and comfort differ from their loved ones and situations arise when discussing those differences may be necessary (Chapin, 2020; Ellison, 2020). This study used the RRM framework to examine factors that might predict how individuals feel about attending events during the pandemic, how these factors might predict the disclosure strategies people use when refusing an invitation to an event, and the relational implications such refusals might have for people's interpersonal relationships.

The first step in applying the RRM to event invitation refusals is to identify factors that might put people in a situation where they need to refuse an invitation. To do this we sought to identify how both situational and relational factors influenced one's comfort level attending an event, as well as their likelihood of attending said event. Two situational factors we posited might predict individuals' feelings and behavior related to an invitation to attend events during the COVID-19 pandemic included the health risk associated with the event and the location where the person lived. Given the importance of accurately understanding risk to discouraging risky behavior (Turner et al., 2011), medical and health personnel have provided the public with assessments of how risky certain behaviors are during the pandemic (Moitke, 2020). Unfortunately, even with this widespread information perceptions of risk still differ across the country and seem to be influenced by the political ideology of the state's leaders. For example, researchers have found differences in steps taken by states to manage the pandemic are influenced by political partisanship (Makridis and Rothwell, 2020), and Hardy (2020) found those who identified as right-wing were less likely to believe it was necessary to engage in recommended hygiene practices. Additionally, Ye (2021) and Adolph et al. (2021) found differences by county and state in vaccination rates and the lifting of stay-at-home orders.

The results of hypothesis one and research question one found that risk level and location did significantly interact to predict comfort levels with events during the pandemic. Specifically, while everyone reported being more comfortable with low-risk activities than moderate or high-risk activities, individuals in California, a blue state, reported lower levels of comfort from the high-risk activities than those from other locations, particularly Oklahoma. Risk level and location also interacted to predict one's likelihood of attending an activity they've been invited to. Again, individuals from all locations showed a clear pattern of a higher likelihood of attending the event in the low-risk activity scenario and reported a lower likelihood in the moderate or high-risk scenario. However, when location was taken into consideration people from Ohio and California reported being less likely to attend the event in the high-risk condition than people from the red state of Oklahoma.

California has maintained strict guidelines throughout the pandemic, particularly when compared to the guidelines in Oklahoma and Ohio. For example, as of November 2020 (shortly after data for this study was collected) California still had a statewide stay at home order and a ban on gatherings, while Oklahoma lifted both its ban and stay at home order and Ohio lifted its stay-at-home order and only maintained its ban on large gatherings (Kaiser Family Foundation, 2020). Additionally, Grossman et al. (2020) found those in democratic-leaning areas 


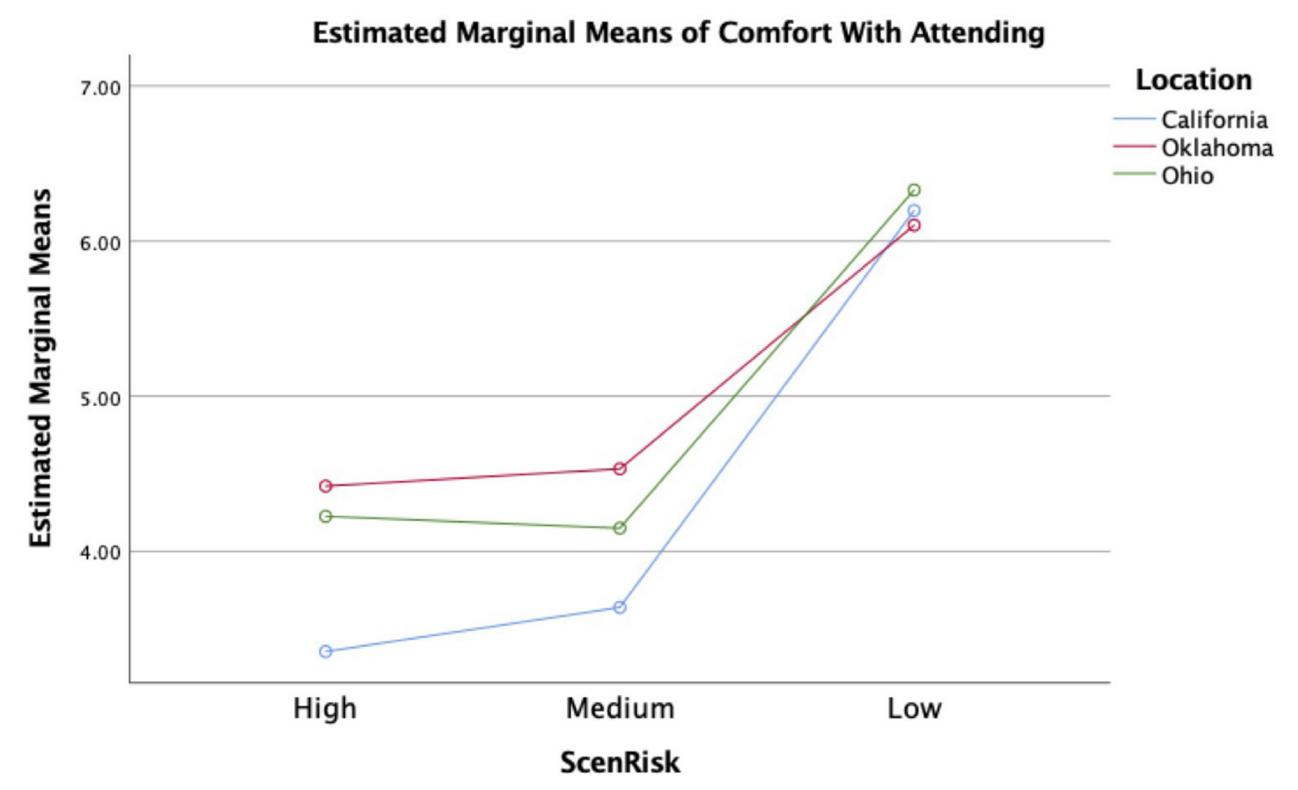

Covariates appearing in the model are evaluated at the following values: Age $=20.574$, Sex $=1.7500$, PercentMask $=86.0865$, GRA $=$

3.3472 , PSS $=2.4930$, Closeness $=5.0704$, AbsValueRiskDiff $=39.3486$

FIGURE 1 | Interaction of risk level and location of data collection to predict comfort attending an event during the COVID-19 pandemic.

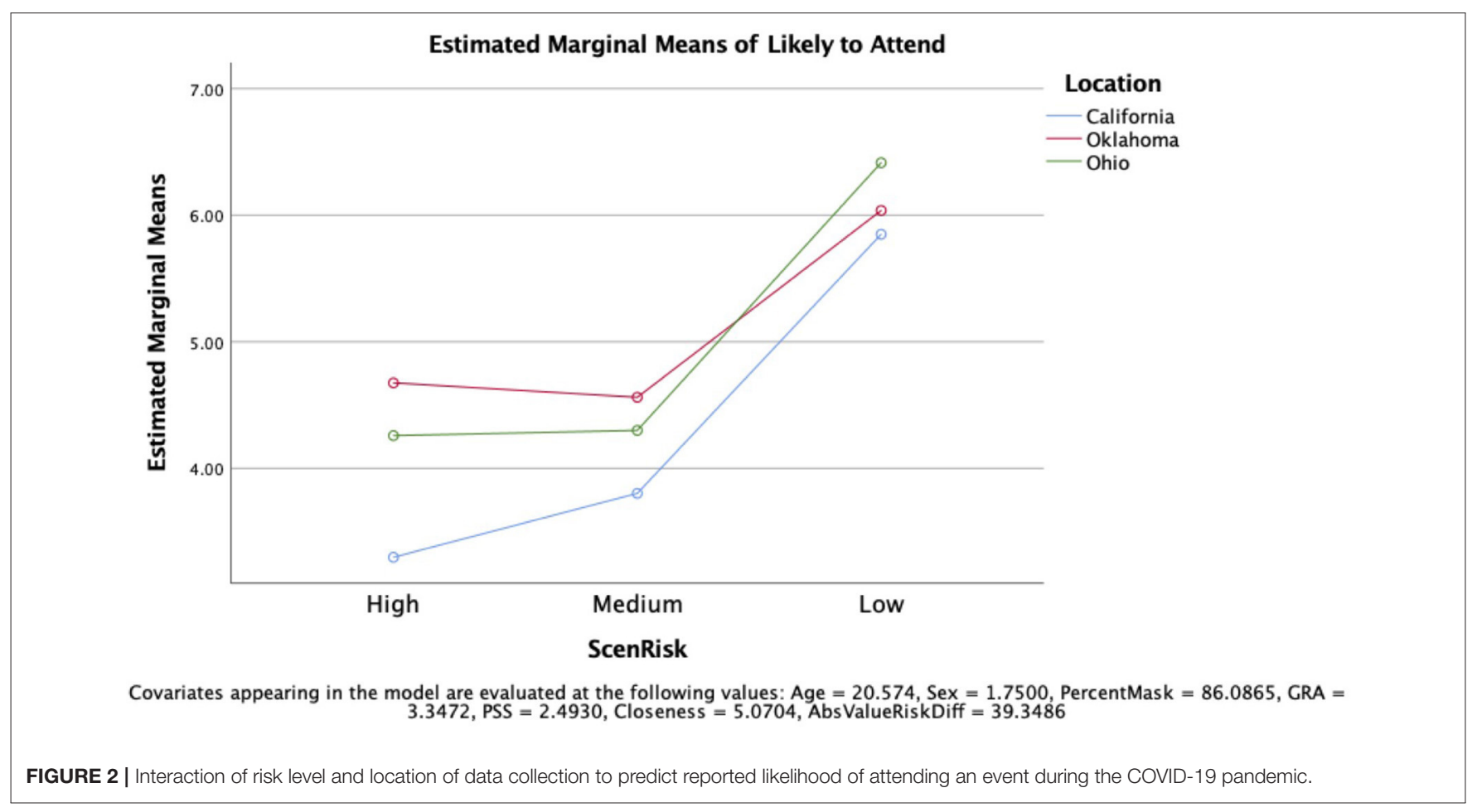




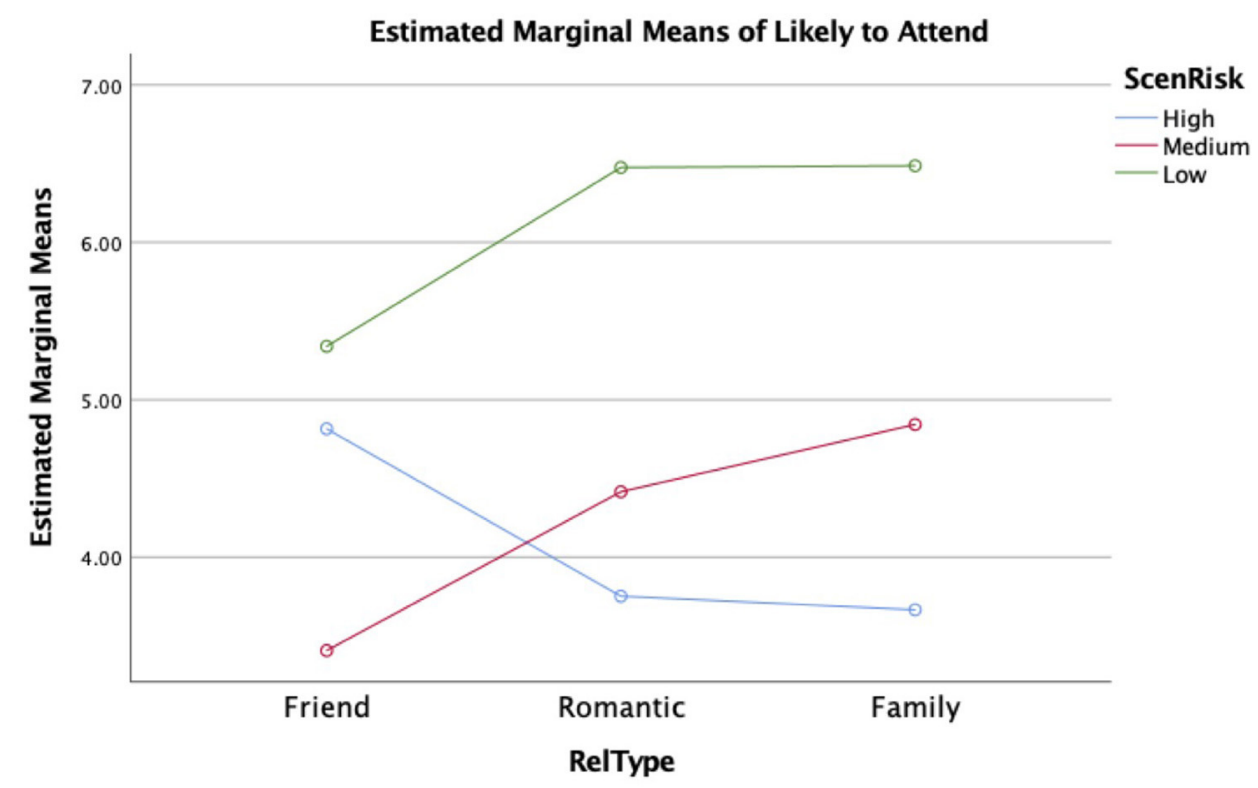

Covariates appearing in the model are evaluated at the following values: Age $=20.574$, Sex $=1.7500$, PercentMask $=86.0865$, GRA $=$ 3.3472 , PSS $=2.4930$, Closeness $=5.0704$, Abs ValueRiskDiff $=39.3486$

FIGURE 3 | Interaction of relationship type and risk level to predict reported likelihood of attending an event during the COVID-19 pandemic.

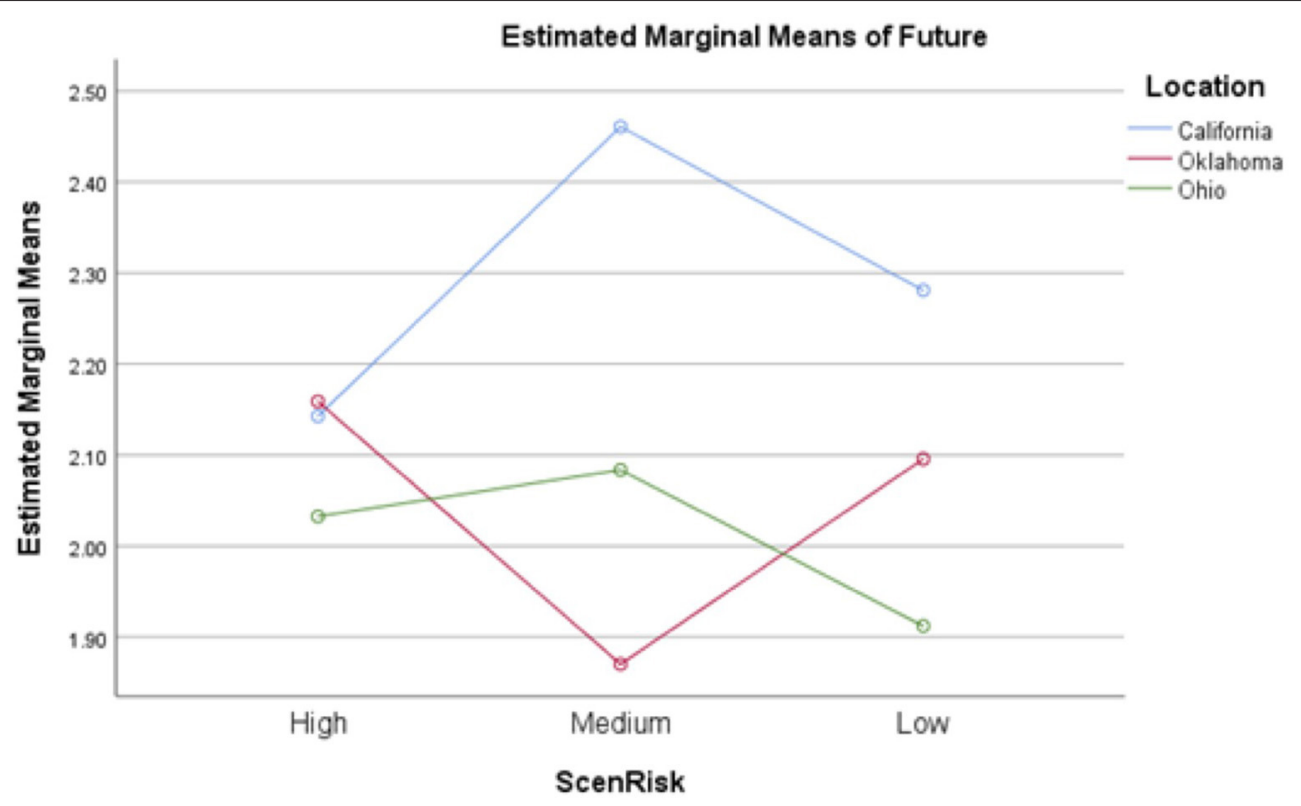

Covariates appearing in the model are evaluated at the following values: $\mathrm{Age}=20.574, \mathrm{Sex}=1.7500$, PercentMask $=86.0865, \mathrm{GRA}=3.3472$, PSS $=2.4930$, Closeness $=5.0704$, AbsValueRiskDiff $=39.3486$

FIGURE 4 | Interaction of risk level and location of data collection to predict reported perceived future relationship implications of an event invitation refusal during the COVID-19 pandemic. 

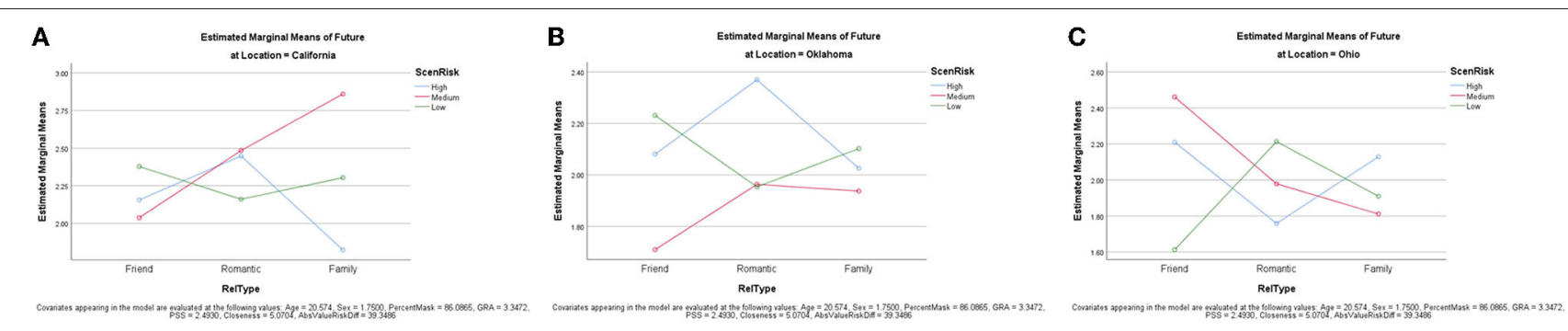

FIGURE 5 | (A-C) Three-way interaction between risk level, type of relationship, and location of data collection to predict reported perceived future relationship implications of an event invitation refusal during the COVID-19 pandemic.

are more likely to be influenced by government safety regulations than those from republican-leaning areas, and the results of this study lend further support to their conclusion.

Relationship of the individual offering the invitation also predicted one's likelihood of attending an event. In general, people were less likely to attend an event when asked by a friend than when asked by a romantic partner or family member. However, this relationship was altered when COVID risk level and relationship were considered in tandem. Specifically, when the activity in question was high-risk, people were more likely to attend said activity when asked by a friend rather than a family member or romantic partner. In the context of event refusals, this means when someone is invited to a high-risk event, they are more likely to find themselves in a situation where they need to provide a refusal when they are invited to that event by a romantic partner or family member than when invited by a friend. Whillans et al. (2020) found when people were invited to an event that made them uncomfortable, they were more likely to accept an invitation from a friend than they were to accept one from a family member or coworker; the results of this study support Whillans et al.'s (2020) conclusions.

There are a few reasons why people would be more likely to attend a risky event when asked by a friend than when asked by their family or romantic partner. First, in Whillans et al.'s (2020) study they found people were more likely to attend high-risk events when asked by a friend because they felt like their friends were less likely to get infected, thus making event attendance seem safer. Perhaps our participants also felt this way. Second, it is possible people spent most of their time with their friends and therefore felt safer spending time with them than they did with others. For example, in order to help people manage the loneliness that many reported experiencing as a result of quarantining at home, public health experts started suggesting people create "coronavirus bubbles," or small groups of people that interact with one another safely (Brueck, 2020). Therefore, these results could be reflective of the bubbles people have created in their lives. Overall, these results suggest that concerns about health risks associated with events, not just for oneself but also for others in attendance, are important and play a role in people's decisions to attend or refuse an invitation.

Importantly, in the context of the RRM, identifying the factors that influence comfort with and likelihood of attending an event during a global pandemic is important because these factors influence whether someone would be in a situation where a refusal would even be necessary. Without this first step, it is impossible for researchers to then consider how these factors influence the likelihood of disclosing a refusal, the strategies used to disclose the refusal, or the relational implications of a refusal. While the three factors examined here are likely not the only relevant ones, this study provides a glimpse into the thought processes people engage in when faced with an event invitation during this time.

The next step in applying the RRM to event invitation refusals was to determine what kind of disclosure strategies people engage in when they do refuse an invitation. Previous research has found refusals can be either direct or indirect, with indirect strategies being more common as they are viewed as polite and face-saving (Tanck, 2002), and we examined this process by considering how truthful people would be when providing an excuse for their refusal. Truthful refusals were considered direct, while untruthful refusals were considered indirect. Although reports of deception were low in general ( $M=1.56$ on a $1-7$ scale), only riskiness of scenario predicted deception level, with people being more likely to report lying about their refusal in the low-risk condition, and people reporting higher levels of truthfulness in the moderate and high-risk conditions. An examination of additional openended data where participants provided the excuse they would give someone when refusing an invitation shows when people lied about their excuse for not attending low-risk events they were likely to say things that suggested they were too busy. For example, when turning down an invitation to go on a walk with a romantic partner one person indicated they would say, "Hey I'm busy with school right now." Additionally, when declining an invitation from a sibling to go to a grocery store where masks were required and social distancing was monitored, one person indicated they would say, "I have a paper due and I'm so far behind on it." Lastly, when declining an invitation to go play tennis with a friend, one person indicated they would say, "I would most likely say I am busy and have other plans going on." Although the authors did not conduct a formal analysis of this open-ended data, it seems as if when people lie, they try to provide an excuse that will limit pushback from their relational partner by suggesting they have other things going on at the time of the event.

Given the importance of saving face when providing a refusal (Tanck, 2002), it makes sense that people would lie in these 
circumstances. The relatively "safe" nature of attending low-risk events means a refusal to an invitation to these events would be more unexpected. Therefore, when people do refuse they are more likely to be concerned about upsetting their relational partner and a lie could be considered one way to honor their own comforts while also limiting the likelihood the invitee will get upset. For example, people are less likely to complain and argue with you if you say you do not have time than if you say you are not comfortable going for a walk. Comparatively, in moderate and high-risk situations, people are more likely to be honest because they probably expect their relational partner to understand their concern. Additionally, these results might reflect the connection between sense of responsibility, blame, and appeasement. For example, Knight (2018) found when people did not feel like they have done anything wrong, but want to avoid blame they communicate in ways that appease a relational partner. Perhaps lying about a reason for not attending a low-risk event is one way people try to appease their relational partners and therefore avoid guilt and blame.

The likelihood people would tell the truth when refusing an invitation to a moderate or high-risk event supports the conclusions of Keating et al. (2013), who found when the circumstances are critical (in this case a moderate or high-risk situation) people are more likely to engage in conversations with a relational partner, even if the topic of conversation is one they might rather avoid. Whillans et al. (2020) found that the main motivator for talking to one's relational partner about their concerns associated with attending events during the COVID-19 pandemic was the risk the event posed, and the results of this study support Whillans et al.'s (2020) conclusions and show that risk concerns outweigh the concerns people might have about being open and honest with their loved ones. If this is related back to the RRM, the perceived risk to others seems to be what motivates people to be truthful, above and beyond the concerns they might have about how they are perceived by their relational partner and/or how their relationship with that person might be impacted.

Finally, in order to account for the importance of relationships in the RRM, we posited that one's event invitation refusal during the age of social distancing might relate to implications for the relationship between the participant and the person extending the invitation. To examine how relationships are impacted by refusals, we tested how our three factors worked together to predict perceptions of future relationship outcomes. Although we predicted that individuals from the red state of Oklahoma might report more negative implications for future interactions, Oklahomans actually reported significantly fewer negative implications for future interactions than people from California or Ohio. This finding reflects the results from hypothesis one that one's location influences perceptions of risk. Out of everyone in this study, participants from Oklahoma reported the most comfort attending high-risk events and were most likely to report being likely to attend a high-risk event. These findings suggest those from Oklahoma viewed COVID19 as less risky than those from other locations, and therefore were less likely to find themselves in a situation where they would have to refuse an invitation to an event in the first place. If they were less likely to refuse an invitation it is also unlikely they would be concerned about conflict or a negative reaction from their relational partner, so it makes sense that many people from Oklahoma reported perceiving positive future interactions with their relational partners.

A three-way interaction (illustrated in Figure 5) found that location and relationship type predicted negative implications for future interactions differently for the three locations. People from Ohio predicted the fewest negative implications with friends in the low-risk condition, while people from Oklahoma predicted the fewest with friends in the moderate-risk condition. Californians, on the other hand, reported the fewest negative implications for family members in high-risk conditions, perhaps suggesting that family members in this blue state might have more similar perceptions in the high-risk condition than the other locations, resulting in less negative implications for refusing an invitation to such an event. However, conclusions regarding this interaction are very speculative and need to be replicated by future research.

\section{Theoretical and Practical Implications}

The results of this study have both theoretical and practical implications. First, the RRM was developed to examine secret disclosure specifically. This study suggests the basic framework of the model can be utilized to examine communication processes in other contexts, specifically when refusing an event invitation. Secret disclosure is a stressful process because it requires people to weigh the pros and cons of letting others in on private information. As Afifi and Steuber (2009) describe, both the decision to disclose and the decision to withhold secrets comes with risk so in order to determine what to do, people consider all of the risks involved. While event invitations are certainly different, this study suggests people do weigh the risks associated with being open and honest about their refusals, with risks about the health and safety of others seemingly being the main motivator. Importantly, this study did not formally test the RRM model and instead applied the basic ideas of the model to the event refusal context. Therefore, in order to add to our theoretical understanding, future researchers interested in this line of scholarship could utilize the list of relevant factors and refusal techniques uncovered here to develop and test a RRM model for refusals specifically.

In terms of practical implications, research suggests being direct and honest when discussing COVID-19 concerns is the best approach for people to use (Whillans et al., 2020), and the results from this study shed some light on situations where people might be more hesitant to be honest. Practitioners, and even journalists, could use this information to help ease people's anxieties about having conversations about COVID-19 related risk and help encourage them to be honest even in low-risk situations. Additionally, it is important to note that Whillans et al. (2020) found people reported feeling closer to their loved ones after discussing their concerns about risk during the pandemic, so even if people are concerned about their relational partner's response, research suggests their worries might be unfounded. 


\section{Future Directions}

Beyond the suggestions mentioned above, future researchers should continue to examine how high-stakes, critical situations influence the likelihood of refusing an event invitation, as well as strategies used to communicate the refusal to close others. In the context of the COVID-19 pandemic, as vaccines become more readily available in the United States it would be interesting to examine how concerns about vaccinations add an additional layer to conversations surrounding event invitations. For example, when considering whether to accept an invitation to an event in addition to considering the riskiness of the event itself, people might now consider whether those in attendance will be vaccinated. This additional concern could add another layer of frustration or concern, particularly for those whose opinions about vaccines differ from the invitee. It would also be interesting to examine the influence of conflict on how people refuse invitations to events in more detail. In this study the authors argued that fear of conflict and negative reactions from one's partner would encourage people to lie about their reasoning for turning down an invitation and were able to gauge those fears by measuring perceptions of future interactions, but asking people about their fears of conflict directly might provide more insight. More generally, future researchers should continue to try to determine what kinds of contexts are considered critical and necessary, and therefore more likely to encourage people to be direct and honest in their refusals rather than indirect. Research on refusals suggests they are more likely to be indirect in order to save face, but this research suggests this might not be the case in some contexts.

\section{Limitations}

This study is not without its limitations. First, in this study the authors utilized location as a proxy for political ideology, and future research should ask participants about their political beliefs directly. Although research supports the idea that location is indeed related to one's political beliefs, of course republicans live in blue states and democrats live in red states. Therefore, measuring for each participant's political beliefs would have provided a more specific and nuanced understanding of how political partisanship influences individual perceptions, as well as their political activity and voting regularity. Additionally, these data were collected from college students, which is not representative of all individuals across the country. Participants were also mostly female, and mostly identified as white. Future researchers should replicate this research in more diverse samples to see if the results are supported. Lastly, this research is based on responses to imagined vignettes, not actual situations that have taken place in people's lives. Therefore, we cannot assume the answers provided in this study perfectly reflect what happens in real life, although given the fact that the data were collected during the pandemic and during the time participants might have had to turn down invitations in real life, those real-life experiences could have influenced how they responded to the vignette scenarios.

\section{CONCLUSION}

Overall, this study utilized the basic RRM framework to examine the role of risk level, one's location within the United States, and relationship type on one's experience with event invitation refusals during the COVID-19 pandemic. Results suggest that all three factors influence one's likelihood of attending an event and perceptions one has of future interactions with their relational partners, while the health risk posed by the event was the most important factor in determining whether someone would be honest or lie when refusing an invitation. The results highlight the influence of perception on the disclosure of refusals and show how important people believe it is to be direct and honest when refusing invitations to high-risk situations. As such, by utilizing the RRM, this study has added to knowledge of the importance of openness and honesty and has expanded our understanding of the refusal process to see how issues such as risk and relationship characteristics influence conversations during a hopefully once in a lifetime pandemic event.

\section{DATA AVAILABILITY STATEMENT}

The datasets presented in this article are not readily available because the authors do not have IRB approval to share the data with others. Requests to access the datasets should be directed to e.n.bostwick@csuohio.edu.

\section{ETHICS STATEMENT}

The studies involving human participants were reviewed and approved by IRB at Cleveland State University, IRB at the University of Oklahoma, and IRB at the University of California, Santa Barbara. The participants provided their written informed consent to participate in this study.

\section{AUTHOR CONTRIBUTIONS}

EB wrote the literature review, method, and discussion. ND created the survey used for data collection, completed the analyses, and created the figures. AJ wrote the analyses up in the results section and provided the accompanying tables. All authors collected data for this piece from their respective institutions, edited the piece, and contributed to the research design and choice of survey items. All authors contributed to the article and approved the submitted version.

\section{FUNDING}

Support for open access publication fees was provided by the University of California Santa Barbara Open Access Fund.

\section{SUPPLEMENTARY MATERIAL}

The Supplementary Material for this article can be found online at: https://www.frontiersin.org/articles/10.3389/fcomm. 2022.742283/full\#supplementary-material 


\section{REFERENCES}

Adolph, C., Amano, K., Bang-Jensen, B., Fullman, N., Magistro, B., Reinke, G., et al. (2021). The pandemic policy u-turn: partisanship, public health, and race in decisions to ease COVID-19 social distancing policies in the United States. Perspect. Polit. 1-23. doi: 10.1017/S1537592721002036

Afifi, T. A., and Steuber, K. (2009). The revelation risk model (RRM): factors that predict the revelation of secrets and the strategies used to reveal them. Commun. Monogr. 76, 144-176. doi: 10.1080/03637750902828412

Afifi, W. A., and Guerrero, L. K. (2000). "Motivations underlying topic avoidance in close relationships," in LEA's Communication Series. Balancing the Secrets of Private Disclosures, ed S. Petronio (Mahwah, NK: Lawrence Erlbaum Associates), 165-180.

Aron, A., Aron, E. N., and Smollan, D. (1992). Inclusion of other in the self scale and the structure of interpersonal closeness. J. Pers. Soc. Psychol. 63, 596-612. doi: 10.1037/0022-3514.63.4.596

Brown, P., and Levinson, S. (1987). Politeness: Some Universals in Language Usage. Cambridge: Cambridge University Press.

Brueck, H. (2020). Winter Is Coming. Start Building Your Coronavirus Bubble Now and Get Ready to Socialize in the Cold. Available online at: https:// www.businessinsider.com/prepare-for-winter-with-the-coronavirus-how-tobubble-2020-9 (accessed November 15, 2020).

Brulle, R. J., Carmichael, J., and Jenkins, J. C. (2012). Shifting public opinion on climate change: an empirical assessment of factors influencing concern over climate change in the U.S., 2002-2012. Clim. Change 114, 169-188. doi: 10.1007/s10584-012-0403-y

Bryson Taylor, D. (2020). A Timeline of the Coronavirus Pandemic. Available online at: https://www.nytimes.com/article/coronavirus-timeline.html (accessed September 30, 2020).

Caughlin, J. P., Afifi, W. A., Carpenter-Theune, K. E., and Miller, L. E. (2005). Reasons for, and consequences of, revealing personal secrets in close relationships: a longitudinal study. Pers. Relationships 12, 43-59. doi: 10.1111/j.1350-4126.2005.00101.x

CDC (2020). Coronavirus Disease 2019 (COVID-10): Personal and Social Activities. Available online at: https://www.cdc.gov/coronavirus/2019-ncov/daily-lifecoping/personal-social-activities.html\#event (accessed November 3, 2020).

Chapin, A. (2020). Have You and Your Friends Had the COVID Talk? Available online at: https://www.thecut.com/2020/07/friends-are-discussing-covid-19rules-before-hanging- out.html (accessed October 20, 2020).

Cohen, S., Kamarck, T., and Mermelstein, R. (1983). A global measure of perceived stress. J. Health Soc. Behav. 24, 385-396. doi: 10.2307/2136404

Darmofal, D. (2005). Elite cues and citizen disagreement with expert opinion. Polit. Res. Q. 58, 381-395. doi: 10.1177/106591290505800302

Derlega, V. J., Winstead, B. A., Mathews, A., and Braitman, A. L. (2008). Why does someone reveal highly personal information? Attributions for and against self-disclosure in close relationships. Commun. Res. Rep. 25, 115-130. doi: 10.1080/08824090802021756

DesOrmeau, T. (2020). From Hair Salons to Gyms, Experts Rank 36 Activities by Coronavirus Risk Level. Available online at: https://www.mlive.com/publicinterest/2020/06/from-hair-salons-to-gyms-experts-rank-36-activities-bycoronavirus-risk-level.html (accessed September 30, 2020).

Dunbar, N. E., and Johnson, A. J. (2015). A test of dyadic power theory: control attempts recalled from interpersonal interactions with romantic partners, family members, and friends. J. Argument Context 4, 42-62. doi: 10.1075/jaic.4.1.03dun

Ellison, K. (2020). Stress from the Pandemic Can Destroy Relationships With Friends- Even Families. Available online at: https://www.washingtonpost.com/ health/stress-from-the-pandemic-can-destroy-relationships- with-friends-even-families/2020/08/07/d95216f4-d665-11ea-aff6-220dd3a14741_story. html (accessed September 30, 2020).

Faasse, K., and Newby, J. (2020). Public perceptions of COVID-19 in Australia: perceived risk, knowledge, health-protective behaviors, and vaccine intentions. Front. Psychol. 11, 551004. doi: 10.3389/fpsyg.2020. 551004

Fetters, A. (2020). Friends are Breaking Up Over Social Distancing: When One Friend Takes Prevention Guidelines More Seriously than the Other, Suspicion, Fear, and Shame Can Drive Them Apart. Available online at: https://www.theatlantic.com/family/archive/2020/04/friends-are-breakingup-over-social-distancing/610783/ (accessed September 30, 2020).

Furman, W., and Buhrmester, D. (1992). Age and sex differences in perceptions of networks of personal relationships. Child Dev. 63, 103-115. doi: $10.2307 / 1130905$

Gadarian, S. K., Goodman, S. W., and Pepinsky, T. B. (2021). Partisanship, health behavior, and policy attitudes in the early stages of the COVID19 pandemic. PLoS ONE 16, e0249596. doi: 10.1371/journal.pone. 0249596

Godbersen, H., Hofmann, L. A., and Ruiz-Fernández, S. (2020). How people evaluate anti- corona measures for their social spheres: attitude, subjective norm, and perceived behavioral control. Front. Psychol. 11, 567405. doi: 10.3389/fpsyg.2020.567405

Grossman, G., Kim, S., Rexer, J. M., and Thirumurthy, H. (2020). Political partisanship influences behavioral responses to governors' recommendations for COVID-19 prevention in the United States. Proc. Natl. Acad. Sci. U.S.A. 117, 24144-24153. doi: 10.1073/pnas.2007835117

Hancock, J., Birnholtz, J., Bazarova, N., Guillory, J., Perlin, J., and Amos, B. (2009). "Butler lies: awareness, deception and design," in Proceedings of the SIGCHI Conference on Human Factors in Computing Systems (Boston, MA), 517-526.

Hardy, L. J. (2020). Connection, contagion, and COVID-19. Med. Anthropol. 39, 655-659. doi: 10.1080/01459740.2020.1814773

Kaiser Family Foundation (2020). State Data and Policy Actions to Address Coronavirus. Available online at: https://www.kff.org/coronavirus-covid-19/ issue-brief/state-data-and-policy-actions-to-address-coronavirus/ (accessed November 3, 2020).

Katella, K. (2020). Taking Your 'Mental Health Temperature' During COVID19. Available online at: https://www.yalemedicine.org/stories/mental-healthcovid-19/ (accessed September 30, 2020).

Keating, D. M., Russell, J. C., Cornacchione, J., and Smith, S. W. (2013). Family communication patterns and difficult family conversations. J. Appl. Commun. Res. 41, 160-180. doi: 10.1080/00909882.2013.781659

Knight, K. (2018). Transgressor communication after committing a hurtful relational event: associations with attributed intent, blame, guilt, responsibility, and perceived forgiveness. Western J. Commun. 82, 475-492. doi: 10.1080/10570314.2017.1325925

Laursen, B., and Williams, V. A. (1997). Perceptions of interdependence and closeness in family and peer relationships among adolescents with and without romantic partners. N. Direct. Child Dev. 78, 3-20. doi: 10.1002/cd.23219977803

Lenz, G. S. (2013). Follow the Leader? How Voters Respond to Politicians' Policies and Performance. Chicago, IL: University of Chicago Press.

Lombardo, C. (2021). In Florida, Texas And Arizona, Defiant School Leaders Are Sticking With Mask Mandates. Available online at: https://www. npr.org/sections/back-to-school-live-updates/2021/08/18/1028863120/ texas-florida-arizona-mask-battles-school-leaders (accessed December 9, 2021).

Makridis, C. A., and Rothwell, J. T. (2020). The Real Cost of Political Polarization: Evidence From the COVID-19 Pandemic. Available online at: https://papers. ssrn.com/sol3/papers.cfm?abstract_id=3638373

Mandrik, C. A., and Bao, Y. (2005). "Exploring the concept and measurement of general risk aversion," in NA- Advances in Consumer Research, eds G. Menon and A. R. Rao (Duluth, MN, Association for Consumer Research), 531-539.

Moitke, M. (2020). From Camping to Dining Out: How Experts Rate the Risks of 14 Summer Activities. Available online at: https://www.npr.org/sections/ health-shots/2020/05/23/861325631/from-camping-to- dining-out-hereshow-experts-rate-the-risks- of-14-summer-activities (accessed September 30, 2020).

O'Reilly, K. B. (2020). Dr. Fauci Outlines 5 Ways to Blunt COVID-19 Pandemic's Resurgence. Available online at: https://www.ama-assn.org/deliveringcare/public-health/dr-fauci-outlines- 5-ways-blunt-covid-19-pandemic-sresurgence (accessed September 30, 2020).

Rader, P. (2019). What are the "Red" and "Blue" (and "Purple") States? Available online at: https://paulrader-42650.medium.com/what-are-the-red-and-blueand-purple-states-ecb9b534cbc6 (accessed December 9, 2021).

Roper, R. R., Johnson, A. J., and Bostwick, E. N. (2018). A target's perspective: verbal aggressiveness, coping strategies, and relational harm. Commun. Res. Rep. 34, 21-28. doi: 10.1080/08824096.2016.1230544 
Tanck, S. (2002). Speech Act Sets of Refusal and Complaint: A Comparison of Native and Non- native English Speakers' Production, 1-22. Washington, DC, TESOL.

Texas Medical Association (2020). TMA Chart Shows COVID-19 Risks for Various Activities. Available online at: https://www.texmed.org/TexasMedicineDetail. asp $x$ ?Pageid $=46106$ andid $=54216$ (accessed July 15,2020$)$.

Turner, M. M., Skubisz, C., and Rimal, R. N. (2011). "Theory and practice in risk communication: a review of the literature and visions for the future," in The Routledge handbook of Health Communication, eds T. L. Thompson, R. Parrott, and J. F. Nussbaum (New York, NY: Routledge), 146-164.

Vai, B., Cazzetta, S., Ghiglino, D., Parenti, L., Saibene, G., Toti, M., et al. (2020). Risk perception and media in shaping protective behaviors: insights from the early phase of the COVID-19 Italian outbreak. Front. Psychol. 11, 563426. doi: 10.3389/fpsyg.2020.563426

Warner, B. R., Warner Colaner, C., and Park, J. (2020). Political difference and polarization in the family: the role of (non)accommodating communication for navigating identity differences. J. Soc. Pers. Relationships 38, 564-585. doi: $10.1177 / 0265407520967438$

Whillans, A., Wilson, A., and Schlager, T. (2020). It's Okay to Say "No" to Events During Covid. Available online at: https://hbr.org/2020/08/its- okay-to-say-noto-social-events-during-covid (accessed September 1, 2020).

Ye, X. (2021). Exploring the relationship between political partisanship and COVID-19 vaccination rate. J. Public Health. doi: 10.1093/pubmed/fdab364. [Epub ahead of print].
Zdanowicz, C., and Jackson, A. (2020). Coronavirus Cases Tied to a Maine Wedding Reception Hit 147, With 3 Deaths. Available online at: https://www. cnn.com/2020/09/05/us/maine-wedding-outbreak-covid-cases-trnd/index. html (accessed October 15, 2020).

Conflict of Interest: The authors declare that the research was conducted in the absence of any commercial or financial relationships that could be construed as a potential conflict of interest.

Publisher's Note: All claims expressed in this article are solely those of the authors and do not necessarily represent those of their affiliated organizations, or those of the publisher, the editors and the reviewers. Any product that may be evaluated in this article, or claim that may be made by its manufacturer, is not guaranteed or endorsed by the publisher.

Copyright (๑) 2022 Bostwick, Dunbar and Johnson. This is an open-access article distributed under the terms of the Creative Commons Attribution License (CC BY). The use, distribution or reproduction in other forums is permitted, provided the original author(s) and the copyright owner(s) are credited and that the original publication in this journal is cited, in accordance with accepted academic practice. No use, distribution or reproduction is permitted which does not comply with these terms. 